\title{
O contexto de exclusão social e de vulnerabilidades de jovens infratores e de suas famílias
}

\author{
Maria Cristina Feijó \\ Universidade do Contestado \\ Simone Gonçalves de Assis \\ Fundação Oswaldo Cruz
}

\begin{abstract}
Resumo
A exclusão social e a delinqüência juvenil têm ocupado amplo espaço na mídia e nas discussões acadêmicas. Na idéia de exclusão inserem-se várias formas de segregação e discriminação, levando a um conjunto de vulnerabilidades difíceis de superar. Este trabalho procura levantar vulnerabilidades do infrator e sua família, assim como algumas relações entre aquelas e o ato infrator. Foi pesquisado, através de entrevistas, o núcleo familiar de 61 jovens infratores do sexo masculino que cometeram atos infracionais graves e que estavam cumprindo medidas sócio-educativas em instituições do Rio de Janeiro e de Recife, em 1997. A pesquisa constatou a fragilidade da maioria das famílias dos entrevistados, que experimentam uma condição de pobreza e exclusão social, ficando isoladas do amparo social. Os jovens e suas famílias sofrem as conseqüências emocionais e financeiras decorrentes da separação dos pais: ausência da figura paterna priva-os do modelo adequado para identidade social; ausência da mãe, por causa de trabalho ou pelo abandono do lar, impossibilita a supervisão apropriada da educação e cuidado dos filhos. As vulnerabilidades da família revelam, também, uma complicada história de agravos à saúde e de violências sofridas.
\end{abstract}

Palavras-chave: delinqüência juvenil; relações familiares; exclusão social; vulnerabilidade familiar

\begin{abstract}
The context of social exclusion and vulnerabilities in delinquent youths and their families. Social exclusion and juvenile delinquency have got much attention in the media and in academic discussions. The idea of exclusion includes many forms of segregation and discrimination, which results into difficult obstacles to overcome. This paper aims at drawing the vulnerabilities of the delinquent and his family, as well as some relations between them and the delinquent act. Semi-structured interviews outlined the family environment of 61 male delinquents, that practiced severe violations and that were imprisoned in institutions of Rio de Janeiro and Recife, in 1997. The research data showed the fragility of the families of most of the subjects, who live in such condition of poverty and exclusion, that they are isolated from any social support. The youths and their families undergo the emotional and financial consequences of parents' splitting: absence of the father deprives them of the adequate model of social identity; absence of the mother, due to work or to home abandonment, makes impossible the proper supervision of education and the care of the children. The vulnerabilities of the family are also made up from a complicated history of diseases and violence.
\end{abstract}

Key words: juvenile delinquency; family relations; social exclusion; family vulnerability

$\mathrm{U}$ ma das possíveis abordagens ao problema complexo da delinqüência juvenil é relacioná-lo com a exclusão social e as vulnerabilidades da família.

O presente artigo relata o resultado de uma pesquisa de campo realizada entre abril e novembro de 1997, quando foram entrevistados 61 jovens infratores que estavam cumprindo medida sócio-educativa em instituições do Rio de Janeiro e Recife. Foram levantados dados sobre o núcleo familiar de cada entrevistado, sendo tratados segundo a técnica de análise de conteúdo. Este trabalho objetiva levantar vulnerabilidades do infrator e sua família, assim como algumas relações entre aquelas e o ato infrator. Antes de discutir os dados da pesquisa, este artigo explicita o pano de fundo teórico da investigação.

\section{O contexto da exclusão social}

A exclusão social tem sido alvo freqüente de debates entre os cientistas e outros intelectuais, em virtude da pobreza e da miséria, cada vez mais visíveis em nosso país. Entre os estudiosos que contribuíram para um arcabouço teórico da 
exclusão, destaca-se Robert Castel (1991, 1995). A idéia de exclusão social assinala um estado de carência ou privação material, de segregação, de discriminação, de vulnerabilidade em alguma esfera. À exclusão associa-se um processo de desvinculação social/espacial. O excluído não escolhe a sua condição; ela se dá numa evolução temporal como resultado das mudanças na sociedade como, por exemplo, as crises econômicas. A segregação étnica constitui por si só problema relevante, trazendo consigo conseqüências, como o desemprego, a falta de alimento, de acesso a serviços de saúde, de moradia adequada, de recursos que possibilitem desempenhar bem papéis na comunidade (Townsend, 1979).

A exclusão pode acontecer sob várias formas. Uma delas e, talvez a mais grave, pois pode gerar outros tipos de exclusão, é a econômica. Quando o país, por questões políticas, administrativas, ou como resultado de um processo mundial, não gera emprego para seus cidadãos, deixa de lado, geralmente, os menos preparados, os que já se encontram em uma zona menos privilegiada. O desemprego estrutural, por sua vez, aliena uma parcela da população que anteriormente se encontrava inserida na sociedade, com papéis definidos.

Algumas outras formas de exclusão são a cultural, a territorial e a étnica. A segregação cultural priva o indivíduo de obter uma escolaridade que é o instrumento para maiores chances de um emprego com melhor remuneração, assim como, de ter acesso a informações que o habilitem a exercer sua cidadania de forma plena. A exclusão territorial afasta o cidadão do convívio com o restante da sociedade, do emprego, da escola e, até, da terra produtiva. A segregação étnica provoca comportamento de revolta entre os indivíduos, classificando-os como seres inferiores e diferentes, impedindo que usufruam plenamente dos bens de consumo, da escola, de serviços de saúde, alijando-os do convívio sadio e produtivo na comunidade.

Todas estas formas de exclusão levam a um conjunto de vulnerabilidades que operam como obstáculos difíceis de superar. Castel (1991) elabora um esquema que se constitui da conjunção de dois vetores: um eixo de inserção/não inserção pelo trabalho e um eixo de inserção/não inserção em uma sociabilidade sócio-familiar. O indivíduo pode estar inserido completamente nos dois eixos (zona de integração), ou pode estar inserido no eixo do trabalho, mas não no eixo da família e/ou da comunidade, e assim por diante. O indivíduo que está desvinculado na esfera do trabalho sofre maiores conseqüências do que aquele desvinculado apenas na área familiar, pois o seu sustento e o de sua família, sua participação na comunidade, assim como todo o funcionamento das relações sociais e da cidadania estão baseados na sua inserção ocupacional. A zona de vulnerabilidade refere-se à precariedade do trabalho e à fragilidade relacional. Na zona de desvinculação o indivíduo encontra-se sem trabalho e em isolamento social: "ao final do processo, a precariedade econômica torna-se privação, a fragilidade relacional isolamento” (Castel, 1991, p. 139).

O ser excluído traduz-se na falta de ganhos, de alojamento, de cuidados, de instrução, de atenção, de poder exer- cer sua cidadania. A falta de oportunidades para o indivíduo e sua família afeta seu sentido de existência e suas expectativas de futuro. Nas palavras de Castel (1995): "nos processos de vulnerabilidade que arruínam os pobres deve ser buscada a origem das perturbações afetando o equilíbrio social”. O primeiro elemento que denota o excluído é ser ele uma pessoa sem inserção no mundo do trabalho. No caso brasileiro, como mostra Oliveira (1997), eles são “os moradores e meninos de rua, os catadores de lixo, os desempregados das favelas e periferias, muitos convertidos em 'flanelinhas' e em delinqüentes” (p. 51).

\section{Vulnerabilidades e delinqüência juvenil: $a$ literatura}

A delinqüência juvenil é o termo internacionalmente utilizado para se referir aos delitos cometidos por adolescentes. No Brasil, após a promulgação do Estatuto da Criança e do Adolescente (ECA), emprega-se o termo infração. Em geral, os autores enfocam o lado econômico, institucional, as políticas públicas, as drogas, e mesmo o aspecto pessoal, como alguns recursos para explicar a infração. A família e suas vulnerabilidades têm sido pouco estudadas no seu relacionamento com a delinqüência, principalmente em nível nacional. Segue, nos próximos parágrafos, uma visão geral, da abordagem da delinqüência.

O arcabouço teórico para explicar a origem da delinqüência, levando em conta a idéia de fatores de risco, pode ser encontrado em Shoemaker (1996), no qual se enquadram as principais linhas teóricas da delinqüência. Tal modelo reúne três níveis de conceitualização.

O nível estrutural atribui a origem da delinqüência a fatores sociais, associados a fatores situacionais e pessoais. Insere-se neste nível a teoria da desorganização social existente nas estruturas e instituições sociais, com maior nitidez nas camadas populares. Esta teoria tenta explicar os delitos cometidos por grupos, organizados em gangues, atribuindo este comportamento à ruptura dos controles sociais tradicionais que operam na comunidade e à incapacidade das organizações para resolver problemas da comunidade coletivamente. Aqui se incluem explicações que privilegiam o aspecto econômico, como a necessidade de sobrevivência. O jovem, seja por abandono ou por pobreza extrema, entraria pelo caminho da infração como forma de sobreviver e aumentar a renda familiar. Outra explicação seria a desigualdade econômica: “... dentro do mesmo nível econômico, os países com maiores índices de desigualdade têm maiores índices de violência” (Werner, 1990, p. 20). Outro aspecto do fator econômico é o desemprego. O mesmo autor levanta questões quanto à real contribuição dos fatores econômicos, pelo menos diretamente, para o aumento da delinqüência. Eles trariam “efeitos sobre formas de organização social” (p. 23).

O nível individual trata das teorias que consideram mecanismos internos do indivíduo como os determinantes do comportamento infrator, tanto nos seus aspectos biológicos, quanto nos psicológicos. Os teóricos que defendem os aspectos biológicos hereditários tratam estes fatores como 
importantes no tocante ao desenvolvimento cognitivo e aprendizagem, podendo predispor o indivíduo à infração, não sendo, porém, determinantes. Aqueles que enfatizam as características da personalidade mostram que seus atributos são fundamentais para a compreensão da delinqüência, ao considerá-los conseqüentes das experiências vividas pelo indivíduo. A personalidade é, então, um misto das influências do meio com a bagagem genética individual. Alguns traços relacionados ao infrator são a impulsividade, a inabilidade nas inter-relações, a ausência de culpa e a insensibilidade à dor alheia e às transgressões. Howard Becker (1977) denomina estes aspectos técnicas de neutralização, ou seja, uma maneira utilizada pelo indivíduo para evitar a confrontação com a opinião das outras pessoas (família, comunidade, sociedade).

O nível sócio-psicológico refere-se à quebra de vínculos sociais do jovem com a família, a escola, a igreja e demais instituições responsáveis pelo controle social do adolescente, à auto-estima e à influência de grupos de jovens sobre o comportamento do infrator. Nesse nível, maior destaque se dá para a família, pois seria ela a instituição capaz de exercer maior controle (estabelecimento de regras, horários, punições e recompensas) sobre o jovem. É neste sentido que se dá a sua importância como fator de risco ou de proteção para a infração.

Werner, Block e Coutinho (1993), Oetting e Donnermeyer (1998) e Schenker e Minayo (2003) atribuem importância fundamental para a família. Segundo esses autores esta é uma instituição que desempenha um papel privilegiado na socialização primária, “cuja proposição principal é o asseguramento de comportamentos normalizados pelo afeto e pela cultura” (Schenker \& Minayo, 2003, p. 300).

Para Werner (1990; Werner et al., 1993), basicamente, há dois aspectos do núcleo familiar que perpassam todos os outros. Um deles é o seu relacionamento, que afeta toda a sua dinâmica. A qualidade do relacionamento familiar é um fator chave no encaminhamento do jovem para a delinqüência. Segundo Werner (1990, p. 36), se o pai está presente, mas a família briga muito e é infeliz, gerando desavenças, rejeição, abandono e outras formas de maus-tratos e problemas psicológicos, há maior probabilidade de algum dos filhos seguir o caminho da infração do que quando o pai não está presente.

Adorno (1997) relata o envolvimento da figura paterna dos infratores com o alcoolismo e, como conseqüência deste, uma dificuldade de relacionamento entre os pais e seus filhos, chegando a episódios de violência física. Constata, também, o que parece ser uma dificuldade, por parte das mães, em se relacionar com os filhos, de uma forma que lhe permita conhecer e lidar com seus traços de personalidade, assim como com os motivos que os levaram à infração. Para elas o filho é sempre bom, carinhoso, reagindo com surpresa frente ao comportamento deste em sociedade.

Outra constatação da pesquisa de Adorno (1997) é a recorrente carência emocional vivida pelos adolescentes infratores. Em um relato de uma mãe, o autor mostra como o jovem vivencia a falta de um membro da família com quem pudesse conversar, desabafar e obter um melhor encaminhamento na vida. O relato mostra, por sua vez, o conformismo ou a falta de capacidade da mãe para perceber a situação emocional e a necessidade de orientação do jovem.

Pedersen (1994), usando um instrumento bastante consagrado na literatura (Parental Bonding Instrument), demonstra que cuidado e controle - aspectos do vínculo familiar - têm uma relação clara com ansiedade/depressão e/ou delinqüência. “A relação é mais forte entre estes sintomas e a percepção de pouco cuidado: pouco cuidado advindo do pai constitui o preditor mais forte de ansiedade/depressão e pouco cuidado advindo da mãe constituindo o preditor mais forte de delinqüência” (p. 986).

O abuso de crianças é outro aspecto da relação familiar. Nas famílias onde há várias pessoas para cuidar das crianças (sejam os pais, os avós, tios ou agregados) há menor probabilidade de as crianças sofrerem maus-tratos, pois o trabalho é dividido entre os membros sem sobrecarregá-los, principalmente quando a prole é numerosa. Quando a mãe cria sozinha seus filhos, a probabilidade de ocorrerem maustratos aumenta; além disso ela se preocupa menos com comportamentos irresponsáveis das crianças, visto que não há como supervisionar de perto cada um dos filhos e, ao mesmo tempo, prover o sustento da família.

O estudo de Meneghel, Giugliani e Falceto (1998), realizado em Porto Alegre, evidencia que os filhos que mais recebem punição física são os mais velhos, os que trabalham fora e pertencentes a famílias de baixa renda. Outrossim, os adolescentes que eram mais punidos tinham oito vezes mais chance de serem violentos com os irmãos. Um maior número de relatos de violência sofrida veio dos jovens da escola pública. As autoras descobriram, também, que os adolescentes considerados agressivos na escola haviam sido mais punidos que os não agressivos. Elas mostram, ainda, que algumas famílias estavam tão despedaçadas que a raiva foi o único sentimento que conseguiam manifestar. As famílias mais punitivas eram as mais rígidas, as que menos dialogavam e as que apresentavam maior número de conflitos entre os irmãos.

Assis (1999) retoma estudo realizado nos Estados Unidos, em 1988, segundo o qual 2,2 em cada 1.000 crianças sofrem maus-tratos psicológicos, em forma de agressão verbal, ameaças e confinamento. Ela diz, ainda, que o reconhecimento e a atenção para este tipo de abuso, dentro do setor saúde no Brasil, datam de pouco tempo. Cita dados de instituições do Estado de São Paulo, revelando que 8,5\% das denúncias são exclusivas deste tipo de violência. As delegacias de polícia do Rio de Janeiro investigadas pela autora nem chegam a receber este tipo de queixa.

As diferenças individuais são profundamente afetadas pela relação pais-filho: Brook, Nomura e Cohen (1989) afirmam que uma relação sem conflitos e afetuosa protege o adolescente da drogadicção, principalmente as drogas pesadas.

O outro aspecto do núcleo familiar é a sua estrutura. Uma dimensão crucial da família é a sua desagregação e problemas econômicos. Citando pesquisas internacionais, Werner (1990) afirma que a separação dos pais está 
correlacionada com as taxas de infração juvenil. As mães que criam seus filhos sozinhas são forçadas a trabalhar fora para sustentar a casa. Por isso, têm menos tempo para vigiar o comportamento da prole, ficando os jovens com "más companhias” e, muitas vezes, buscando dinheiro nas ruas. A desagregação familiar também causa problemas psicológicos que levam à delinqüência, seja por conflitos quanto à identidade sexual, seja por falta de atenção e carinho interpretados como rejeição, ou seja pela "necessidade das crianças adotarem uma atitude mais ‘valente’ para proteger a casa” (p. 36).

Outra conseqüência da ausência do marido é a "circulação de crianças”. As mães, muitas vezes, mandam os filhos morar em casa de parentes ou em instituições, ou por não terem condições de criar todos os filhos, ou quando se juntam com outro companheiro, que não está disposto a criar enteados.

\section{Exclusão social, vulnerabilidades da família e a delinqüência: uma pesquisa}

\section{Aspectos Metodológicos}

Este trabalho é um recorte de uma pesquisa mais ampla, que deu base para a tese de doutorado da primeira autora (Feijó, 2001), realizada com a participação de pesquisadores do Centro Latino-Americano de Estudos de Violência e Saúde (CLAVES/FIOCRUZ). Na pesquisa-mãe foram também entrevistados 31 irmãos dos infratores, cujos dados não foram utilizados aqui, por fugir dos objetivos deste artigo.

A equipe multiprofissional de pesquisadores compôsse de uma médica, quatro psicólogas, um sociólogo, todos com nível de especialização em psicologia ou epidemiologia e saúde pública, além de três estagiárias de psicologia.

Foram realizadas duas entrevistas semi-estruturadas com cada jovem, totalizando 61 infratores, sendo 50 no Rio de Janeiro e 11 em Recife. A duração média da sessão de entrevista foi de 60 minutos, todas realizadas nas instituições onde estavam acautelados. Os adolescentes estavam cumprindo medida sócio-educativa de internação ou semi-internação, pelos seguintes atos infracionais, previstos no Código Penal (Brasil, 1986): homicídios (artigo 121CP), tentativa de homicídios (artigo 121, 14 II CP), roubo qualificado (artigo 157 CP) e lesões corporais graves (artigo 129, parágrafos 1, 2 e $3 \mathrm{CP}$ ), estupro (artigo $213 \mathrm{CP}$ ) e tráfico de drogas (artigo $12 \mathrm{CP}$ ). A faixa etária dos infratores concentrou-se entre 13 e 18 anos, estando 50\% nos 17 anos. Sua escolaridade variou entre a $1^{\text {a }}$ e a $8^{\underline{a}}$ série do ensino fundamental, sendo que, na realidade, a maioria dos jovens relatou ter problemas para ler e escrever.

A dificuldade em lembrar fases da vida ficou muito evidente, bem como a falta de hábito de falar de suas experiências, especialmente de lembrar os fatos em ordem cronológica. Esta impossibilidade também foi encontrada por Belém, Faria, Rizzini e Chalhub (1998), entrevistando jovens que cometeram atos infracionais leves no Rio de Janeiro. Contudo, a mobilização dos sentimentos esteve sempre presente, expressando-se em suas faces, na gesticulação das mãos, no lacrimejar dos olhos, nas reticências dos relatos, demonstrando o quanto os temas abordados tocavam fundo em suas vidas.
Reiteradas vezes se ouviu dos jovens a afirmação de que tinha sido a primeira vez em suas vidas que alguém os ouvia falar sobre si próprios por tanto tempo. Sentiam-se finalmente prestigiados e escutados. Os infratores estavam tão habituados a falar do ato infracional, que muitas vezes começavam a relatá-los sem que isso fosse solicitado, demonstrando certa surpresa quando se começava a perguntar sobre sua vida inteira e seus sentimentos, desde o nascimento.

Terminada a etapa de trabalho de campo, o processamento das informações contidas nas entrevistas foi efetuado através da transcrição e organização dos dados para a aplicação da técnica de análise de conteúdo, na sua vertente análise temática, segundo Bardin (1977). Nesta técnica, determinam-se as unidades de significado com o propósito de chegar ao objeto de estudo proposto, agrupando-os em unidades temáticas que darão origem a categorias, as quais foram analisadas e discutidas na última sessão à luz da literatura concernente ao tema. Esta técnica de análise permite, também, o cálculo de freqüências, que fornecem dados cifrados (Bardin, 1977). Da leitura exaustiva do material do núcleo familiar surgiram as categorias que serviram de base para a análise: (1) estrutura, (2) relacionamento familiar, (3) cuidados iniciais, (4) violência física, (5) maus-tratos psicológicos, (6) aspectos econômicos, (7) escolaridade da família, (8) história familiar de agravos à saúde e (9) história familiar de envolvimento infracional.

Os nomes que aparecem no texto são fictícios, para proteger a identidade dos jovens.

\section{Resultados}

Com relação à categoria estrutura, pôde-se constatar que a grande maioria dos entrevistados provém de famílias divididas, em que os pais se separaram, os genitores muitas vezes abandonaram os filhos e suas mães ou morreram, ou formaram outras famílias, com novo companheiro e novos filhos advindos desta união. Em 21,3\% dos casos os pais vivem juntos. São famílias em que a infra-estrutura é prejudicada, quer seja em termos financeiros, emocionais ou domiciliares. Muitas vezes, pela falta do pai, a mãe tem que ir em busca de um trabalho, deixando, assim, as crianças aos cuidados de outros, quando não de si próprias.

A figura do pai é ausente em 37,7\% destas famílias, quer seja porque ele tenha morrido e o jovem nem sequer o conheceu; quer seja porque ele tenha abandonado a família: "Mãe eu tenho, pai não. Meu pai eu não conheci, não" (Cristian); "Meu pai morreu eu tinha 1 ano" (Dener).

Em termos da categoria relacionamento familiar, foi verificada uma rede de problemas de relações interpessoais, de comunicação entre os pais e destes com seus filhos e da família em geral. Em se tratando de relações familiares, os infratores entrevistados revelaram uma gama de desentendimentos e desafetos das famílias envolvidas. Esta problemática nos envia a pensar no grau de influência que os fatores familiares exercem no envolvimento do jovem com a infração.

O primeiro detalhe que nos chama a atenção é o fato de os adolescentes demonstrarem certa dificuldade em falar 
sobre seus sentimentos e sobre a maneira como os membros da família se relacionam entre si e como eles se relacionam com a família. Muitas vezes eram usados apenas monossílabos ou poucas palavras para responder a tais perguntas. Alguns jovens conseguiam elaborar mais suas respostas, fazendo verdadeiros relatos de suas histórias. Porém, grande parte não conseguia fornecer mais do que pequenas respostas e, até por vezes, não conseguia fornecer qualquer resposta. Este fato pode ser devido não apenas à baixa escolaridade destes jovens, mas também à sua dificuldade em lidar com as questões afetivas e emocionais, característica mais presente no gênero masculino.

Houve um caso em que o adolescente se recusou, em certo ponto da entrevista, a responder sobre sua família: "Se quiser perguntar sobe mim... Eu não quero falar sobre a minha família, não. Já chega essas técnicas que enchem o meu saco perguntando isso.” (Dener). Este jovem não tem qualquer laço com a família. Mora em uma casa junto com outros traficantes e não manifestou qualquer desejo de voltar a contatá-la. Deixou transparecer, entretanto, certa mágoa em virtude de sua família não procurá-lo, "não querer saber dele".

No tocante ao relacionamento com o pai, $45,9 \%$ dos entrevistados relataram possuir uma relação afetiva com o genitor: "Adoro, amo demais meu pai..." (Clodoaldo); "Ele é amoroso comigo. Ele gosta de me dar conselho pra sair dessa vida” (Cláudio). Em contrapartida, surgiram alguns relatos (17\%) de jovens que não demonstram ter um bom relacionamento com a figura paterna: "Meu sangue não combina com o dele" (Dalton). Há ainda aqueles (35\%) que relataram ter contato esporádico ou nenhum contato com o pai e aqueles que o pai é falecido ou sumido.

A grande maioria (82\%) afirmou se dar bem com a mãe: "Amo demais a minha mãe. Sinto tudo por ela. Dou minha vida por ela" (Clodoaldo); "Sempre ia ver a minha mãe, todo dia, que eu não consigo ficar sem ver a minha mãe, senão eu fico triste..." (Benedito). E alguns destes defendem a mãe no relacionamento com o pai ou padrasto. A imagem que muitos destes jovens têm das mães parece um tanto idealizada, descrevendo a mãe como uma figura sem defeitos, encontrando explicações para todos os comportamentos inadequados das mães. Se a mãe usa de violência, a culpa é do jovem que fez "coisa errada". O relacionamento com a figura materna é descrito como bom e a mãe como paciente, conselheira. Alguns dizem que a mãe é preocupada em dar conselho para que o jovem não entre, ou então, saia da vida do crime, para que ele não use drogas e não se envolva com "más companhias". A mãe, que geralmente provê sozinha, ou ajuda no sustento da família, é valorizada pelo jovem como a mãe que deu tudo para ele, que se sacrificou e criou os filhos sozinha. Mesmo as mães que não trabalham, ou que tiveram ajuda do pai ou do padrasto, são vistas como a provedora em um sentido mais amplo, como aquela que dá afeto, que dá estrutura à família, que zela pelos filhos.

Apenas três entrevistados disseram achar o relacionamento com a genitora insatisfatório: "A relação com a minha mãe é boa, mas não é muito não, porque eu ainda precisa- va do apoio dela, que ela nunca criou a gente. Eu não sei nem o que é ter uma família...” (Brian).

Outros dois jovens revelaram ter um mau relacionamento com a mãe: "Eu não gosto dela... Ela nem liga pra mim... desde que eu era pequeno." (Douglas); "O que você sente quando pensa na sua mãe? - Revolta por ela não ter cuidado da gente.” (Dener). Cinco infratores disseram que suas mães faleceram ou abandonaram o lar.

Dos jovens que relataram ter padrasto (22), alguns (7) afirmaram manter um bom relacionamento com ele: "É que nem o relacionamento como se fosse o meu pai” (Célio); "Meu padrasto é mais atencioso do que meu pai. É um corre danado. Ele está sempre correndo atrás. Não sei, vou embora agora dia 18" (Dagmar). Outros 7 disseram manter um relacionamento razoável: "É bem, mas às vezes a gente briga por coisinha que não vale a pena brigar. Não é aquela briga de cair na porrada. É discussão... a gente discute agora, daqui a 3 segundos a gente já está brincando" (Cristiano).

Os jovens que não se dão bem com o padrasto somam 17,4\%: "É outra pessoa que eu sou doido pra matar" (Bruno); "Ah, não sei. Ele é muito chato. Se eu pudesse matar, eu matava” (Bernardo). Observou-se no relato destes jovens que há ciúme em relação à mãe. Alguns o dizem de forma aberta, outros o sentem veladamente e não querem admitir. Porém, não toleram a idéia de suas mãe terem se unido a outro homem que não seus pais verdadeiros.

De acordo com os relatos, $78,6 \%$ dos jovens não têm madrasta. Dos que disseram ter, alguns infratores afirmam se relacionar bem com a madrasta e outros jovens dizem não ter boa convivência: "Não se dou muito não, porque eu não gosto dela. Ela é muito chata” (Bartolomeu).

Dos $21,3 \%$ dos pais que vivem juntos, $4,9 \%$ brigam e $18 \%$ parecem conviver bem. "Ah, tia, pra falar a verdade, vive e não vive. Meu pai sempre chega: 'ah! Que a culpa é sua, que não sei o que’. Minha mãe sempre tem que ficar escutando o que ela não quer escutar. Ter que ficar escutando desaforo do meu pai...” (Danilo). "Era bom, super bom. Minha mãe saía pra pescar com a gente. Saíamos todos juntos. A gente brincava. Era super bom com todos os filhos” (Carlos).

Em 26,2\% das entrevistas, os pais são separados, não se dão bem e não mantêm contato: "Antigamente ele ia lá em casa. Agora ele está morando com a família dele” (Dario). Alguns entrevistados revelaram que os pais são separados, mas se dão bem, continuando um relacionamento amigável, ou pelo menos, provendo para os filhos.

O relacionamento com a família estendida teve respostas bastante diversificadas. Há relatos de jovens que não têm contato com a família do pai, em função do mau relacionamento com este ou de seu falecimento. Em certos relatos, os jovens atestam ter melhor relacionamento com a família da mãe. Outros dizem que mantêm bom relacionamento com ambos os lados. Aqueles que não têm bom relacionamento ou sequer convivência com a família estendida de ambas as partes somam $13,1 \%$. Há quatro casos em que os jovens dizem ter mais relacionamento com a família do pai do que com a família da mãe. Em 16,4\% das entrevistas, os infratores res- 
pondem que têm relacionamento razoável com pouco contato com a família estendida. O que se notou é a pouca convivência desses jovens com a família estendida, principalmente tios e a família paterna. Este dado, na maioria dos casos, não é devido à migração da família ou à distância geográfica.

Finalmente, em termos de relacionamento, apenas $36,1 \%$ foram perguntados sobre se gostariam de fazer alguma mudança na família, se pudessem. Houve três respostas básicas. Uma se refere à vontade de que existisse mais união entre os seus membros: "Ah, mais unida um pouco. Que a minha família é muito boa na arena. Muito fofoqueira; um inventando mal contra o outro.” (Dionísio). Outra resposta foi a de permanecer da mesma maneira: "Está bom desse jeito mesmo... já me acostumei desse jeito deles. Não é um jeito ruim" (Cristiano). A terceira resposta registra a vontade de que a família mude para melhor de alguma forma, seja em termos de relacionamento, de dinheiro ou de organização: "Deveria... minha família... eu acho que todos esses problemas são conseqüência de um mau planejamento... não tinha assim... uma boa base estruturada, entende?...” (Cícero).

Observou-se que há um padrão comum à maioria dos jovens entrevistados, com relação aos cuidados iniciais: eles não tiveram os cuidados da mãe na maior parte do tempo, seja porque a mãe trabalhava, seja porque ela não demonstrava interesse ou afeto pelo filho. Geralmente, eles eram deixados com alguém da família. O jovem podia ficar com as(os) irmãs(os) mais velhas(os), com a avó, ou com uma tia, enquanto a mãe saía para trabalhar. Poucos adolescentes foram deixados em creche ou com alguma pessoa fora da família. As crianças que foram cuidadas pela mãe, desde bebê, perfazem 19,6\%. Em um caso não havia supervisão adequada na higiene, alimentação e, em muitos casos, na freqüência escolar. Muitos relatam que passavam o dia na rua brincando, engajando-se em atividades ilícitas e entrosando-se com "más companhias", ainda que dissessem para a mãe que iam para a escola. Em alguns casos, a mãe consentia em que o filho não freqüentasse mais as aulas, deixando uma falha no cuidado com o futuro do filho.

Tratando-se de violência familiar, podemos dizer que a maioria dos infratores entrevistados sofreu algum tipo de agressão em casa. Alguns, logo que perguntados, diziam que nunca haviam apanhado. Porém, quando foram mais investigados, diziam que ou o pai, ou a mãe, ou ambos já haviam perpetrado algum tipo de punição física sobre o filho, ainda que mais leve. Isto nos dá a idéia de que o apanhar ficaria mais marcado na memória ou no sentimento destas pessoas, quando $o$ ato tivesse uma intensidade maior, a ponto de deixar marcas físicas. Um dado curioso é muitos acharem o apanhar um fato normal da vida, principalmente quando o ato é infligido pela mãe.

Em 26,2\% dos casos houve relato de violência por mais de um membro da família, seja pai, mãe, avô/avó, tia/tio, irmãos ou padrasto. A figura que mais pune fisicamente, seja de forma leve ou de modo bem mais severo, é a mãe e, em segundo lugar, vem o pai como figura punitiva.

Investigando-se a ocorrência de maus-tratos psicológicos, descobriu-se ser a maior parte relatos de rejeição.
Verificou-se em 17,4\% das entrevistas a ocorrência de rejeição somente, seja pelo pai, mãe, irmão ou tios. Houve também episódios de rejeição aliados a ser aterrorizado, tanto pelo pai quanto pela mãe. Alguns relataram se sentir rejeitados quando a mãe morreu ou quando os pais se separaram. Em um caso, o jovem diz ter se sentido isolado, deixado de lado pela família. Dois jovens relataram terem visto o pai espancar e humilhar a mãe, fato que podemos tomar como maus-tratos psicológicos, uma vez que a criança se sente acuada e impotente diante da violência sofrida pela provedora. Constatou-se, também, a agressão verbal com desqualificação da criança ou do jovem.

A idéia que se depreende das entrevistas é a de que esses jovens repetem o comportamento de seus pais e seus avós, no relacionamento com os filhos, com a companheira e com a família em geral. Dos jovens entrevistados no Rio de Janeiro, 21,8\% já têm filhos e, nenhum deles mora com o adolescente: $50 \%$ dos filhos moram com a mãe e a outra metade mora com alguém da família materna: "Desde pequenininha? Você chegou a morar com a mãe da sua filha? - Cheguei, ela estava morando lá em casa. Depois eu briguei com ela, aí ela foi embora" (Denilson). "Uma menina? Você sabe o nome? Nem o nome eu sei. - Quanto tempo tem isso? - Dois anos e pouco. - Você achou boa a idéia de ter uma filha sem conviver com ela? - Sem conviver acho que é ruim. Eu fico com vontade de ver, eu não sei nem onde ela mora, não tem nem como ver.” (Benício)

No que se refere aos aspectos econômicos, em sua grande maioria, os infratores entrevistados pertencem a uma classe social baixa, sem maiores recursos, e as ocupações de seus componentes refletem trabalho não-especializado, com baixa remuneração.

Apenas 8,7\% destes jovens vêm de famílias de classe média baixa. Estes adolescentes relatam possuir bens distintos dos demais, como melhores condições de moradia, carro, seguro saúde, televisão, videocassete, aparelho de som. Em $4,4 \%$ destes relatos, os infratores revelam que os pais possuem renda de imóvel(eis) alugado(s).

As condições de moradia dos jovens variam, porém a maioria, embora refira possuir casa própria, reside em locais menos privilegiados da cidade, em favelas e bairros mais pobres. Muitos relatam que suas casas são feitas de tijolo, sendo algumas, pintadas, outras somente emboçadas, outras sem emboço, outras parte de madeira e parte de tábua e algumas só de tábuas.

Alguns jovens revelam que passaram sérias dificuldades quando crianças ou adolescentes mais jovens, como falta de comida e uma infra-estrutura econômica para suprir as necessidades básicas da família.

Encontrou-se o pai como único provedor financeiro da família em 17,4\% das entrevistas. Algumas vezes, o pai é auxiliado com algum tipo de ajuda material por parte da(o) avó(ô). As profissões exercidas são diversas, tais como: feirante, segurança, cobrador de ônibus, motorista, comerciante, encarregado da CERJ, lanterneiro, atracador de navio, embarcado da Petrobrás, vendedor, padeiro e mestre de obras.

Em 51\% das entrevistas a mãe é uma figura importante para a manutenção material do lar, como trabalhadora. A mãe 
foi tida como a única provedora (quando nem pai/padrasto ou filhos trabalham) do lar em 10,9\% dos casos. Ela também conta, algumas vezes, com a ajuda de uma pessoa da família estendida, quer seja a avó, o avô ou o pai, ainda que este seja separado da mãe. As profissões encontradas são: doméstica, cozinheira, dona de salão, manicura, faxineira, comerciária, professora primária e secretária.

Há relatos (10) em que se encontra o pai/padrasto e a mãe trabalhando, sendo os que trazem o sustento para o lar. Há casos (10) em que somente os pais/padrastos e filhos trabalham. As profissões encontradas são: encarregado de fábrica de cerâmica, dono de firma de conserto de fotocopiadoras, servente de pedreiro, enfermeira, aposentado, babá, pedreiro, operária, eletricista, funcionário da CEDAE, mensageiro de hotel e artesão. Os casos em que mãe e filhos trabalham perfazem $6,7 \%$.

Em 13,2\% das entrevistas, encontramos maior parte da família trabalhando (pai/padrasto, mãe e filhos, ainda que não todos os filhos). As ocupações relatadas são: vigia, jardineiro, pintor, motorista de táxi, soldado do exército, contínua, costureira, caminhoneiro, vidraceiro, além de outras já citadas. As famílias em que só os filhos trabalham somam 8,7\%. Pais desempregados ou renda familiar vinda apenas do produto da infração (tráfico) aparecem em 4,4\% das vezes. Em apenas um caso não foi possível identificar o tipo de ocupação ou de onde vem a renda da família.

Outro aspecto em que verificamos a vulnerabilidade familiar é a escolaridade da família. Como se pode ver na Tabela 1, a escolaridade dos pais e das mães desses adolescentes é bastante baixa. Os irmãos apresentam uma escolaridade pouco maior que os infratores, em virtude destes serem, em sua grande maioria, mais velhos, tendo tido oportunidade de conviver com o pai e ter a supervisão da mãe, como foi constatado nas entrevistas com os irmãos, na pesquisa-mãe. Poderíamos, talvez, depreender deste fato que os adolescentes teriam, por sua vez, uma baixa escolaridade, em função do exemplo fornecido pelos provedores.

Tabela 1

Escolaridade da família nuclear dos infratores (em \%)

\begin{tabular}{|c|c|c|c|}
\hline Escolaridade & Pais & Mães & Irmãos \\
\hline Analfabeto & 2,2 & 8,7 & - \\
\hline Não estudam & - & - & 4,4 \\
\hline $\begin{array}{l}\text { Estudam ou estudaram } \\
\text { (s/ inf. do nível) }\end{array}$ & - & - & 19,6 \\
\hline $\begin{array}{l}\text { Sabem ler e escrever } \\
\text { (s/ inf. do nível) }\end{array}$ & 15,3 & 17,4 & 8,7 \\
\hline $1^{\mathrm{a}} \mathrm{a} 4^{\mathrm{a}}$ série & - & - & 15,3 \\
\hline $5^{\mathrm{a}}$ a $8^{\mathrm{a}}$ série & 8,7 & 8,7 & 21,8 \\
\hline $\begin{array}{l}2^{\underline{0}} \text { grau (completo ou } \\
\text { incompleto) }\end{array}$ & 6,7 & 4,4 & 15,3 \\
\hline $\begin{array}{l}\text { Superior (completo ou } \\
\text { incompleto) }\end{array}$ & 2,2 & - & 4,4 \\
\hline
\end{tabular}

Com relação aos agravos à saúde, os infratores relataram doenças sem especificação em primo e pai; problemas psiquiátricos envolvendo tio, mãe e avô; problemas neurológicos com o próprio jovem, irmão e tio; câncer do avô; alcoolismo relacionado ao pai, mãe e tia; dependência de drogas da tia; seqüelas na locomoção de um primo por ter sido baleado; derrame da mãe e um caso em que o irmão recém-nascido morreu por ter caído das mãos do pessoal técnico do hospital.

O envolvimento da família dos adolescentes em atos infracionais está descrito na Tabela 2. Chamam a atenção os $51,7 \%$ de familiares que têm envolvimento com drogas. Os adolescentes que não relatam qualquer história de envolvimento infracional familiar somam 10,9\%.

Tabela 2

Atos infracionais pregressos na família dos infratores

\begin{tabular}{lc}
\hline \multicolumn{1}{c}{ Atos infracionais } & Porcentagem \\
\hline Assalto (pai, irmão, tio) & 12,2 \\
Furto (irmão) & 2,2 \\
Preso (s/ inf. do ato - primos, pai, tio) & 10,4 \\
Jogo do bicho (pai, avô) & 4,4 \\
Homicídio (irmão, pai, cunhado) & 8,2 \\
Drogas (irmão, tios, padrasto, mãe, pai, primos) & 51,7 \\
\hline
\end{tabular}

Os relatos de história de violência na família incluem suicídio do irmão, acidente de carro com irmão ou mãe, espancamento sofrido pela mãe e assassinato de pai, tios, primos e irmão. Um dos infratores expressou seu sentimento e sua elaboração ao falar sobre o assassinato do tio da seguinte forma: “Ah, eu fiquei triste e fiquei pensando em tudo. Aí eu falei, aí minha mãe falou 'isso é coisa da vida’. Aí eu fui compreendendo. Aí hoje eu nem penso mais nisso. Eu procuro não pensar mais nisso” (Célio).

\section{Discussão}

Os dados encontrados neste trabalho foram também relatados na pesquisa realizada pelo grupo do CEDEC com jovens de São Paulo, referenciada no trabalho de Violante (1989). Entre algumas das vulnerabilidades das famílias observadas estão: desqualificação para o trabalho, desemprego, instabilidade ocupacional, baixo nível de escolaridade, analfabetismo, ausência do pai, ausência da mãe, dificuldade de relacionamento do jovem com sua família.

\footnotetext{
Nestas condições assumem proporções drásticas a rejeição e a intolerância dos adultos em relação à criança, levando-os a abandoná-la ou interná-la numa entidade assistencial. Portanto, além das condições materiais, são também precárias as condições assistenciais e afetivas sob as quais o menor vive, condições estas necessárias ao seu desenvolvimento físico e psicológico. (p. 45)
} 
Um dado relevante que se constatou é o fato de que todos os adolescentes infratores entrevistados apresentaram baixa escolaridade e todos eles pararam de estudar antes de entrar para a vida infracional. Muitos repetiam o ano duas a três vezes e desistiam. Outros tinham problemas com os professores; outros, ainda, eram forçados a trocar de escola em função da mudança de domicílio e deixavam de estudar, talvez por não se adaptarem a um novo ambiente. Conforme nos dizem Arpini \& Quintana (2003) “problematiza-se o modo como se constrói a identidade desses adolescentes, tendo em vista que as condições sociais de marginalidade em diferentes planos proporcionam bases muito frágeis para a construção de identidades positivas” (p. 28).

De maneira geral, o modelo aprendido por estes jovens é aquele em que a mãe e o pai não se dão, brigam e há violência dos pais e de outros membros da família para com os filhos. Violência esta, muitas vezes utilizada para extravasar as frustrações, a impotência e a raiva acumuladas de uma vida sem vislumbre de dias melhores, de desrespeito e mágoas vividos. Segundo Mielnik (1993), a manifestação da violência surge não repentinamente, mas de forma lenta e progressiva.

O imaginário social destes jovens é o aprendido em casa e na comunidade, o qual eles passam adiante para seus filhos e, mais tarde, para seus netos. Muza (1996) relata a história de uma adolescente que reproduz a sua experiência de abandono na infância com seu próprio filho. Sendo o único modelo a que o jovem tem acesso, há dificuldade no desenvolvimento de vínculos afetivos com o outro.

A família tem como papel preponderante a educação dos filhos, a orientação para o desenvolvimento de suas potencialidades e a direção no convívio social. São os pais que ajudam os filhos no crescimento sadio, na conquista de maturidade e da autonomia (Mielnik, 1993).

A mãe é a figura básica e essencial, não só na concepção, mas em todo o processo de desenvolvimento e educação da criança. Seu relacionamento com o filho tem início desde a gravidez, continuando por toda a vida. Como foi visto, pelo menos em metade das famílias as mães trabalhavam fora para complementar a renda, vinda ou do pai, ou da ajuda de algum outro familiar, sendo que em 10,9\% dos casos ela era a única provedora. Com isto ausentavam-se do lar, prejudicando a adequada supervisão dos jovens.

O pai, por sua vez, desempenha um papel igualmente importante sobre a criança, não apenas como principal provedor material, pois sua figura tem aspectos sociais relevantes para a formação de seu filho. Ele transmite à criança a idéia de força, segurança, proteção e um afeto distinto daquele advindo da mãe. O pai que demonstra carinho, compreensão e tranqüilidade influi no equilíbrio e saúde da criança, desde a concepção. Além disso, fornece o apoio e suporte que a mãe necessita para desempenhar seu papel.

O pai que não impõe limites e é ausente no estabelecimento de ordem e de conduta moral, traz ao jovem uma imagem de abandono, rejeição e solidão, resultando-lhe uma exigência interna paralisante e atormentadora. $\mathrm{O}$ que freqüentemente acontece é o homem não acompanhar as constantes mudanças socioculturais que mexem com o papel do homem e da mulher e, assim, ele termina por perpetuar o seu antigo papel de manutenção das condições materiais da família, deixando à mãe o equilíbrio emocional dos filhos (Muza, 1996).

A união do casal é primordial na construção de um lar equilibrado e saudável. É importante que os filhos percebam harmonia e solidez na estrutura familiar. Os pais têm o papel de orientar os filhos quanto às condutas éticas, motivações, seus direitos e deveres, sua vida espiritual, sexual, social e outros aspectos que o ser humano aprende e consolida ao longo de sua formação.

É comum nestas famílias as freqüentes trocas de emprego e de ocupação, assim como períodos em que há falta de trabalho e remuneração. Este quadro é suficiente para o estabelecimento de um clima emocional instável, cujos componentes são a insegurança e a frustração. Isto configura uma situação propícia para ruídos na comunicação dos indivíduos do grupo familiar e, por conseqüência, possibilidades de fracasso no desempenho de papéis familiares (Muza, 1996).

Gilligan (1996), em seu livro Violence: our deadly epidemic and its causes, relata que os criminosos violentos são objeto de violência desde a mais tenra infância. Eles viram parentes próximos serem assassinados, foram torturados, estuprados, com inúmeros sofrimentos familiares. Diz o autor que o grau de violência e crueldade a que foram expostos estes homens na infância é tão extremo e incomum, que dá um novo significado ao termo abuso infantil.

Observamos que muitos jovens entrevistados não se sentiam confortáveis em falar sobre abusos e violências sofridos. Alguns, como dito antes, chegaram a dizer que nunca haviam sofrido violência e, depois, relataram as surras e palmadas vivenciadas. Não foi investigada, por isso, qualquer história de abuso sexual vivida por estes jovens. A violência parece ser algo tão comum nas famílias e comunidades destes adolescentes, que, muitas vezes, ela passa como algo natural e inevitável na vida. Esses jovens aprendem em suas casas, com os vizinhos, com sua comunidade, que a maneira de se agir diante de algo que não lhes agrada é com a violência. Eles viam seus avós, seus pais e seus irmãos fazendo isso com outros e com eles mesmos. Trata-se de um modelo aprendido que faz parte do imaginário social destes adolescentes, desde crianças, ocorrendo, assim, o que se chama de circularidade da violência, que passa de geração a geração e de uma camada social a outra.

Em relação aos maus-tratos psicológicos, qualquer avaliação depende grandemente do contexto sociocultural. Em geral, um comportamento é considerado psicologicamente abusivo, quando ele transmite uma mensagem culturalmente específica de rejeição ou prejudica um processo psicológico socialmente relevante, tal como o desenvolvimento de um autoconceito positivo e coerente. A questão da inserção étnica e cultural é importante para se estabelecer fronteiras na definição de maus-tratos, assim como a idade é importante para avaliar severidade (Garbarino, Guttman \& Seeley, 1986). 
As famílias nas quais ocorrem maus-tratos psicológicos, geralmente vivem isoladas de influências "naturalmente corretivas", criadoras de sistemas de apoio pró-social. Freqüentemente, a família se isola da comunidade, ou a comunidade ou os vizinhos também rejeitam e isolam a família. Não há senso de responsabilidade coletiva e identidade de vizinhança. As condições dominantes são: pobreza, desemprego, crime, condições precárias de moradia e indisponibilidade de serviços.

Pressionadas pela sua situação de vida diária e subjugada pelas responsabilidades dos cuidados com as crianças, estas famílias tendem a perder quaisquer habilidades positivas de enfrentar a situação construtivamente e a cair num padrão crescente de maus-tratos. Estas famílias não estão socialmente isoladas em sentido estrito, mas elas estão isoladas do amparo social construtivo e do mundo que está além da sua comunidade de baixos recursos.

As vulnerabilidades encontradas nesta pesquisa estão associadas a um contexto de exclusão social em que vivem as famílias dos infratores entrevistados. Podem-se encontrar na literatura sobre delinqüência juvenil vulnerabilidades semelhantes, geralmente vivenciadas por pessoas das minorias e com precária inserção social (Cotten et al., 1994; Fergusson \& Lynskey, 1996; Ferreira \& Marturano, 2002; Gomes, Deslandes, Veiga, Bhering, \& Santos 2002; Tinklenberg, Huckaby, \& Tinklenberg, 1996). Neste contexto, a qualidade de vida destes indivíduos fica bastante comprometida. Ainda que os dados desta pesquisa tenham sido coletados no ano de 1997, infelizmente o que se constata ainda hoje, na mídia e nas pesquisas mais recentes (Ferreira \& Marturano, 2002; Gomes et al., 2003; Poletto \& Koller, 2002), são as mesmas condições de vida e vulnerabilidades vividas pelas famílias e pelos jovens, como a falta de recursos financeiros, materiais e afetivos, e de apoio por instituições públicas.

Faz-se necessário o desenvolvimento de mais pesquisas, assim como de programas sociais e de saúde que lidem com as vulnerabilidades destas famílias, ensinando-as, entre outras coisas, a desenvolver mecanismos para lidar com suas carências e sentimentos de incompetência. Um exemplo de prevenção terciária, utilizando os conceitos da Abordagem Centrada na Pessoa, pode ser encontrado no trabalho de Bezerra e Linhares (1999), em relação ao uso de drogas. Os autores criaram uma abordagem que ajuda os pais de jovens drogacditos a desenvolver competência para resolver o problema do uso de drogas do filho, tornando a família "poderosa em promover mudanças verdadeiras em todo o sistema familiar" (p. 187). Bezerra e Linhares acreditam que "os vínculos dos pais com os filhos são mais poderosos em operar mudanças que qualquer vínculo terapêutico ou de autoridade constituída” (p. 187). Outro exemplo de trabalho usando as técnicas rogerianas são as oficinas educativas para a promoção da saúde em adolescentes, propostas por Serra e Cannon (1999). Estas oficinas objetivam a apreensão de conhecimento e a mudança de atitudes, sendo estruturadas sob os conceitos de ludicidade, criatividade, liberdade de expressão, postura educativa transformadora, conscientização, integração grupal, construção do próprio saber, reflexão crítica, respeito aos valores individuais e socioculturais e desenvolvimento da auto-estima.

Segundo Feijó (2001), os conceitos e atitudes da abordagem rogeriana, juntamente com os conceitos e as técnicas da abordagem social-cognitiva, se bem aglutinados em programas de tratamento, prevenção e promoção da saúde, podem ser um instrumento valioso no enfrentamento da infração juvenil.

\section{Referências}

Adorno, R. C. F. (1997). Caracterização das famílias de autores de atos infracionais da Febem/S.P. Relatório de pesquisa não-publicado. Faculdade de Saúde Pública/USP, São Paulo.

Arpini, D. M., \& Quintana, A. M. (2003). Identidade, família e relações sociais em adolescentes de grupos populares. Estudos de Psicologia (PUC-Campinas), 20(1), 27-36.

Assis, S. G. (1999). O percurso da violência na história ocidental: infância e saúde. Horizontes, 17, 11-77.

Bardin, L. (1977). Análise de conteúdo. Lisboa: Edições 70.

Becker, H. S. (1977). Uma teoria da ação coletiva. Rio de Janeiro: Zahar Editores.

Belém, R., Faria, S., Rizzini, I., \& Chalhub, T. (1998). Adolescentes em conflito com a lei: o caso do Rio de Janeiro. Relatório Final de Pesquisa não-publicado, Universidade Santa Úrsula / Juizado da Infância e Juventude, Rio de Janeiro.

Bezerra, V. C., \& Linhares, A. C. B. (1999). A família, o adolescente e o uso de drogas. In N. Schor, M. S. T. Mota, \& V. C. Branco (Orgs.), Cadernos Juventude Saúde e Desenvolvimento (Vol. 1, pp. 184-196). Brasília: Ministério da Saúde.

Brasil. (1986). Código de Processo Penal ( $7^{\mathrm{a}}$ ed). Rio de Janeiro: Forense.

Brook, J., Nomura, C., \& Cohen, P. (1989). A network of influences on adolescent drug involvement: neighborhood, school, peer and family. Genetic, Social and General Psychology Monographs, 115(1), 125-145.

Castel, R. (1991). De l’indigence à l'exclusion, la désaffiliation: précarieté du travail et vulnerabilité relationnelle. In J. Donzelot (Org.), Face à l'exclusion - le modèle français (pp. 137-168). Paris: Esprit.

Castel, R. (1995). L'avènement d'un individualisme négatif. Magazine Literaire, 334, julho/agosto.

Cotten, N. U., Resnick, J., Browne, D., Martin, S., McCarraher, D. R., \& Woods, J. (1994). Aggression and fighting behavior among African-American adolescents: individual and family factors. American Journal of Public Health, 84(4), 618-622.

Feijó, M. C. C. (2001). Raízes da violência: a importância da família na formação da percepção, da motivação e da atribuição de causalidade de adolescentes infratores e de seus irmãos não infratores. Tese de Doutorado não-publicada, Escola Nacional de Saúde Pública/Fundação Oswaldo Cruz, Rio de Janeiro.

Fergusson, D. M., \& Lynskey, M. T. (1996). Adolescent resiliency to family adversity. Journal of Child Psychology and Psychiatry, 37(3), 281-292.

Ferreira, M. C. T., \& Marturano, E. M. (2002). Ambiente familiar e os problemas do comportamento apresentados por crianças com baixo desempenho escolar. Psicologia: Reflexão e Crítica, 15(1), 35-44.

Garbarino, J., Guttman, E., \& Seeley, J (1986). The psychologically battered child. San Francisco: Jossey-Bass.

Gilligan, J. (1996). Violence: our deadly epidemic and its causes. Nova York: Grosset/Putnam.

Gomes, R., Deslandes, S. F., Veiga, M. M., Bhering, C., \& Santos, J. F. C. (2002). Por que as crianças são maltratadas? Explicações para a prática de 
maus-tratos infantis na literatura. Cadernos de Saúde Pública, 18(3), 707714.

Meneghel, S. N., Giugliani, E. J., \& Falceto, O. (1998). Relações de violência doméstica e agressividade na adolescência. Cadernos de Saúde Pública, 14(2), 327-335.

Mielnik, I. (1993). Mãe, pai e filhos: encontros e desencontros. São Paulo: Hucitec.

Muza, G. (1996). Alcoolismo e drogadicção na adolescência: histórias de vida. Tese de Doutorado não-publicada, Faculdade de Medicina de Ribeirão Preto, Universidade de São Paulo.

Oetting, E. R., \& Donnemeyer, J. F. (1998). Primary socialization theory: the etiology of drug use and deviance. Part I. Substance Use and Misuse, 33(4): 995-1026.

Oliveira, L. (1997). Os excluídos “existem”? Notas sobre a elaboração de um novo conceito. Revista Brasileira de Ciências Sociais, 33, 49-61.

Pedersen, W. (1994). Parental relations, mental health and delinquency in adolescents. Adolescence, 29(116), 975-990.

Poletto, R. C., \& Koller, S. H. (2002). Rede social de apoio e afetivo de crianças em situação de pobreza. Psico, 33(1), 151-175.

Schenker, M., \& Minayo, M. C. S. (2003). A implicação da família no uso abusivo de drogas: uma revisão crítica. Ciência \& Saúde Coletiva, 8(1), 299-306.
Serra, A. S. L., \& Cannon, L. R. C. (1999). Pelo andar se faz um caminho! Uma proposta metodológica de educação em saúde para adolescentes. In N. Schor, M. S. T. Mota, \& V. C. Branco (Orgs.), Cadernos Juventude, Saúde e Desenvolvimento (Vol. 1, pp. 276-288). Brasília: Ministério da Saúde.

Shoemaker, D. J. (1996). Theories of delinquency - an examination of explanations of delinquent behavior. Nova York: Oxford University Press.

Tinklenberg, J. A., Huckaby, W. J., \& Tinklenberg, J. R. (1996). Criminal recidivism predicted from narratives of violent juvenile delinquents. Child Psychiatry and Human Development, 27(2), 69-79.

Townsend, P. (1979). Conceptualising poverty. In P. Townsend (Org.), The international analysis of poverty (pp. 27-39). Nova York: Harvester Wheatsheaf.

Violante, M. L. (1989). O dilema do decente malandro. São Paulo: Cortez.

Werner, D. (1990). Para as origens do crime urbano: estudos internacionais sobre as causa sociais do crime e suas implicações num caso brasileiro de menores carentes. Relatório de pesquisa para CNPq não-publicado, Departamento de Ciências Sociais, Universidade Federal de Santa Catarina, Florianópolis.

Werner, D., Block, E. M., \& Coutinho, M. R. (1993). Antecedentes familiares e crime. Relatório de pesquisa para CNPq não-publicado, Departamento de Ciências Sociais, Universidade Federal de Santa Catarina, Florianópolis.

Maria Cristina Feijó, doutora em Saúde Pública pela Escola Nacional de Saúde Pública da Fundação Oswaldo Cruz, é professora do Mestrado multidisciplinar em Ciências da Saúde, da Universidade do Contestado, Campus Concórdia, Santa Catarina. Endereço para correspondência: Rua Victor Sopelsa, 3000, Bairro Salete; Concórdia, SC; CEP 89700-000. Fone: (49) 441-1055. Fax: (49) 441-1020. E-mail: cfeijo@uncnet.br Simone Gonçalves de Assis, doutora em Saúde Pública pela Escola Nacional de Saúde Pública da Fundação Oswaldo Cruz, é pesquisadora adjunta do CLAVES/ENSP/FIOCRUZ.E-mail: simone@claves.fiocruz.br 